\title{
Estimation of Economic Burden of Cataract Disease in Iran: A Cross- sectional Research
}

\author{
Ali Asghar Shakeri ${ }^{1}$, Ali Akbari Sari ${ }^{2}$, Maryam Radin Manesh $^{3}$, Ghasem Fakhraei ${ }^{4}$, Ahmad \\ Fayazbakhsh $^{5}$, Alireza Yousefi ${ }^{* 6}$
}

1. MSc in Health Economics, Department of Health Management and Economics, School of Public Health, Tehran University of Medical Sciences, Tehran, Iran

2. Associate Professor, Department of Health Management and Economics, School of Public Health, Tehran University of Medical Sciences, Tehran, Iran

3. PhD Candidate in Health Economics, Vice chancellor of Management Development Resource Planning, Tehran University of Medical Sciences, Tehran, Iran

4. Associate Professor, Department of Ophthalmology, Farabi Eye Hospital, Tehran University of Medical Sciences, Tehran, Iran

5. Associate Professor, Department of Health Management and Economics, Paramedical School, Tehran University of Medical Sciences, Tehran, Iran

6. PhD Candidate in Health Management Services, Department of Health and Treatment Services Management, School of Management and Medical Information Sciences, Shiraz University of Medical Sciences, Shiraz, Iran

Article Type:

Short Communication

Article History:

Received: 5 Jul. 2017

Revised: 3 Apr. 2018

Accepted: 23 May. 2018

\section{*Correspondence:}

Alireza Yousefi, Department of Health and Treatment Services Management, School of Management and Medical Information Sciences, Shiraz University of Medical Sciences, Shiraz, Iran Alirezayusefi67@gmail. com

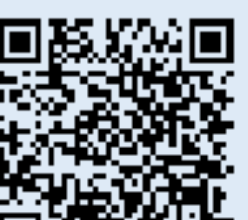

\begin{abstract}
Background and objectives: Cataract disease is among the conditions that impose a substantial economic cost on countries every year due to their high prevalence rate. The prevalence of this disease has caused significant direct and indirect costs. This study aimed to estimate the economic burden caused by the costs of the cataract disease. Methods: This descriptive, analytical, and cross-sectional study was conducted on patients with cataract disease in Farabi Hospital of Tehran, Iran in 2014. Data were collected using the cost-determination checklist, a questionnaire, and interviews with experts, and previous studies in this field. In addition, the Prevalence-based and social capital approaches were exploited to estimate the economic burden and costs of the cataract disease, respectively. Costs were divided into three types of medical expenses, patient and family expenses, and productivity lost costs. Data analysis was performed in Excel software.

Results: The economic burden of the cataract disease was estimated at 6202529401500 rials. Results demonstrated that the hospitalization costs were significantly higher, compared to the other costs related to the cataract disease.

Conclusion: According to the results of the study, the economic burden associated with the cataract disease was equal to $0.13 \%$ of the gross domestic product and included $2.43 \%$ health expenditure of Iran in 2010 .
\end{abstract}

Keywords: Cataract, Economic Burden, Cost

Copyright $($ C 2018, Jorjani Biomedicine Journal has published this work as an open access article under the terms of the Creative Commons Attribution License (http://creativecommons.org/licenses/by-nc/4.0/) which permits noncommercial uses of the work while it is properly cited. 



\section{Introduction}

Recent statistics show that approximately 284 million people in the world have visual impairments, $90 \%$ of who reside in developing countries (1). The cataract disease is one of the main causes of blindness in the world and the most prevalent eye disease (2). Cataract is a medical condition in which the lens of the eye becomes progressively opaque, resulting in reduced visual acuity or damage to visual function. The most common treatment for this disease is removing the lens inside the eye and replacing it with an artificial intraocular lens (3).

In the United States, more than 1.35 million cataract surgical procedures were paid for by Medicare during 1990-1991, in a way that an annual cost of $\$ 3.4$ billion has been estimated for this surgery and associated cares $(4,5)$. The only source of research in this area in Iran is the study by Hashemi et al., in which the prevalence rate of cataract in adults aged more than 40 years in Tehran was reported at $22.7 \%$ (6). In addition, Sari et al. estimated the number of cataract surgeries to be 556 cases per 100,000 populations (7). The ultimate goal of estimating the burden of diseases is to provide the objective evidence needed for policymaking, design and management of health plans, prioritization of strategic research in the area of community health, development and allocation of human and financial resources, expansion of institutional capacities to design, implementation and evaluation of costeffective interventions for prevention, and treatment and rehabilitation of diseases (8). With this background in mind, this study aimed to accurately estimate the economic costs of cataract in 2014 in Iran.

\section{Materials and Methods}

This descriptive, analytical, and crosssectional research was conducted in 2014 using the information of the year 2012. In order to estimate the economic burden, we used the prevalence-based approach (with regard to the occurrence of cataract). In addition, the social perspective approach was exploited to estimate the costs. In general, the costs were divided into three groups of medical costs, costs imposed on the patients and their families, and costs due to productivity lost. However, there was no need for routine calculation of the sample size to estimate the economic burden of diseases, and samples were merely sample data. In the present study, 100 hospitalized patients and 100 outpatients were selected randomly and continuously to estimate the outpatient treatment costs. In addition, the research questionnaire was completed by 100 outpatients referring to the cataract clinic of Farabi Eye Hospital and their companions.

In these studies, the mean direct and indirect costs of each patient were calculated and used to estimate the costs of the community of patients since service tariffs and treatment protocols in the country are the same and can be generalized. Data collection tools included a checklist prepared from the costs on the hospital bill, a questionnaire to collect data related to the costs of patients and their families, and information presented in other studies and websites (global bank, Statistical Center of Iran, and Organization for Civil Registration), applied to estimate some required data, including the prevalence of the disease and patient mortality rate.

In order to estimate the costs, the following stages were passed:

1. The previous studies in this area were used to estimate the prevalence rate of the disease. In addition, other epidemiological data were 
extracted from previous research and through interviews with ophthalmologists.

2. In order to determine the pathological aspects and treatment models of cataract in Iran, we evaluated the relevant texts and medical files existing in Farabi Eye Hospital and interviewed experts of the field. In the end, the treatment model was determined using common drug and laser therapies by evaluating 100 medical files in Farabi Hospital.

A: In order to calculate the medical costs (diagnostic, surgery, drug therapy and followup costs), estimations were carried out, as follows: diagnostic tests for cataract were determined and the total diagnostic costs of each patient were estimated based on the public sector tariffs. In addition, the total diagnostic costs of cataract in 2012 in Iran were calculated using the prevalence rate of the disease. Afterwards, the mean surgery cost was extracted from the medical files and was multiplied by the number of operated patients, estimating the total surgery costs of cataract in 2012. The only treatment option for cataract is surgery. The medications consumed during the treatment process were divided into two groups of prescribed and non-prescribed drugs. Following that, the mean cost of prescribed medications and nonprescribed medications was estimated using the medical files of patients and a questionnaire, respectively.

In terms of follow-up costs, the model of follow-up care for the post-treatment phase was applied, and the relevant costs were estimated using the incidence and prevalence rates and medical tariffs in 2012. For employed patients, the mean employee wage of the same year was estimated.

\section{Results}

In this study, $53 \%$ of the patients were female and the rest were male. In addition, $43 \%$ of the patients were from Tehran province, whereas $27 \%$ of the subjects were from Alborz province and the rest were from other provinces of Iran. In terms of the level of education, $49 \%$ of the patients were illiterate. In addition, $77 \%$ of the participants were married, $48 \%$ were housewives, and $47 \%$ were covered by social security insurance. About half of the cataract patients received IOLM diagnostic services, and $85 \%$ of the subjects were in the surgery group. In total, 95 out of 100 patients were accompanied by a companion when referring to the hospital. Furthermore, more than half of the patients (64\%) had outbound travels to receive cataract-related cares, and $55 \%$ of the subjects were forced to spend at least one night out of their homes to receive the required services. In addition, $72 \%$ of the patients used their personal cars to refer to the clinic. Moreover, 58 patients (58\%) spent one-two days to receive a visit and medication services, and $98 \%$ of the subjects used their savings to pay the service costs. Furthermore, 2\% of the patients were forced to take loans. It is worth noting that $35 \%$ of the patients' companions were self-employed.

The direct medical costs, including outpatient treatment costs, for both surgery and nonsurgery groups and the hospitalization costs, are presented in Table 1, respectively. 
Table 1. Estimation of Outpatient Treatment Costs per each Cataract Patient

\begin{tabular}{|l|l|}
\hline Type of Cost & Cost (rial) \\
\hline $\begin{array}{l}\text { Outpatient Treatment } \\
\text { Cost per each Patient } \\
\text { (Surgery Group) }\end{array}$ & $\mathbf{4 7 6 2 4 0}$ \\
\hline Cost of diagnostic tests & $(263180)$ \\
\hline $\begin{array}{l}\text { Outpatient treatment } \\
\text { cost* }\end{array}$ & $(209900)$ \\
\hline $\begin{array}{l}\text { Mean visit cost } \\
\text { (multiplied by the mean } \\
\text { number of visits 1.23) }\end{array}$ & $1.23 * 37000=(45510)$ \\
\hline $\begin{array}{l}\text { Mean medications cost } \\
\text { (multiplied by the mean } \\
\text { number of visits 1.23) }\end{array}$ & $1.23 * 133650=(164390)$ \\
\hline $\begin{array}{l}\text { Cost of medications } \\
\text { without a prescription }\end{array}$ & $(3160)$ \\
\hline $\begin{array}{l}\text { Outpatient Treatment } \\
\text { Cost per Each Patient } \\
\text { (Non-surgery Group) }\end{array}$ & 85340 \\
\hline $\begin{array}{l}\text { Mean visit cost } \\
\text { (multiplied by the mean } \\
\text { number of visit 1.07) }\end{array}$ & $1.07 * 5500=(58850)$ \\
\hline $\begin{array}{l}\text { Mean medications cost } \\
\text { (multiplied by the mean } \\
\text { number of visit } 1.07)\end{array}$ & $1.07 * 19930=(21330)$ \\
\hline $\begin{array}{l}\text { Mean cost of } \\
\text { medications without a } \\
\text { prescription }\end{array}$ & $(5160)$ \\
\hline
\end{tabular}

The cost of outpatient treatment is obtained from the total average cost of the visit and medications. To avoid mistakes and recalculation, sub-items are presented in brackets.

In addition, the mean cost of hospitalization was estimated at 12339800 rials per patient (Table 2).
Table 2. Estimation of Hospitalization Costs per each Cataract Patient

\begin{tabular}{|l|l|}
\hline Type of Cost & Cost (rial) \\
\hline $\begin{array}{l}\text { Mean Hospitalization Cost of a } \\
\text { Patient (Surgery Group) }\end{array}$ & 12339800 \\
\hline Mean visit cost & $(37000)$ \\
\hline Mean hospitalization cost & $(486000)$ \\
\hline $\begin{array}{l}\text { Mean cost of a companion in the } \\
\text { hospital }\end{array}$ & $(210000)$ \\
\hline Mean surgery cost & $(2464000)$ \\
\hline Mean costs of routine tests & $(225500)$ \\
\hline Mean surgery visit cost & $(182000)$ \\
\hline Mean counselor visit cost & $(182000)$ \\
\hline Mean cost of anesthesia & $(1150000)$ \\
\hline Mean cost of operating room & $(1232000)$ \\
\hline Mean cost of a technician & $(492800)$ \\
\hline Mean cost of f/u for a week & $(18500)$ \\
\hline Cost of IOL purchase & $(2610000)$ \\
\hline Mean cost of hospital gowns & $(150000)$ \\
\hline $\begin{array}{l}\text { Mean cost of purchasing } \\
\text { operating room equipment }\end{array}$ & $(2900000)$ \\
\hline
\end{tabular}

The direct non-medical costs were estimated at 720210 and 274660 in the surgery and nonsurgery groups, respectively. On the other hand, the indirect productivity lost cost for outpatients, operated patients and companions was 360000, 430000, and 210600, respectively. In general, 830000 cataract patients refer to hospitals annually, 416790 of who are in the surgery group ad 413210 are in the non-surgery group. The total outpatient treatment cost of the surgery and non-surgery groups and total direct non-medical and indirect costs (productivity lost) are presented in Table 3. 
Table 3. Estimation of Total Cost Related to Cataract Patients in Iran

\begin{tabular}{|l|l|}
\hline $\begin{array}{l}\text { Total Outpatient Treatment } \\
\text { Cost }\end{array}$ & Cost (rial) \\
\hline $\begin{array}{l}\text { Total outpatient treatment cost } \\
\text { (surgery group) }\end{array}$ & 1984920699600 \\
\hline $\begin{array}{l}\text { Total outpatient treatment cost } \\
\text { (non-surgery group) }\end{array}$ & 35263341400 \\
\hline Total hospitalization cost & 5143105242000 \\
\hline Total direct non-medical cost & 413668584500 \\
\hline $\begin{array}{l}\text { Total indirect cost } \\
\text { (productivity lost) }\end{array}$ & 412000164000 \\
\hline Total costs & 6202529401500 \\
\hline
\end{tabular}

After comparing the costs of cataract patients, it was demonstrated that the hospitalization costs accounted for about $83 \%$ of the total costs, and the other three categories did not include more than $17 \%$ of the costs (Diagram $1)$.

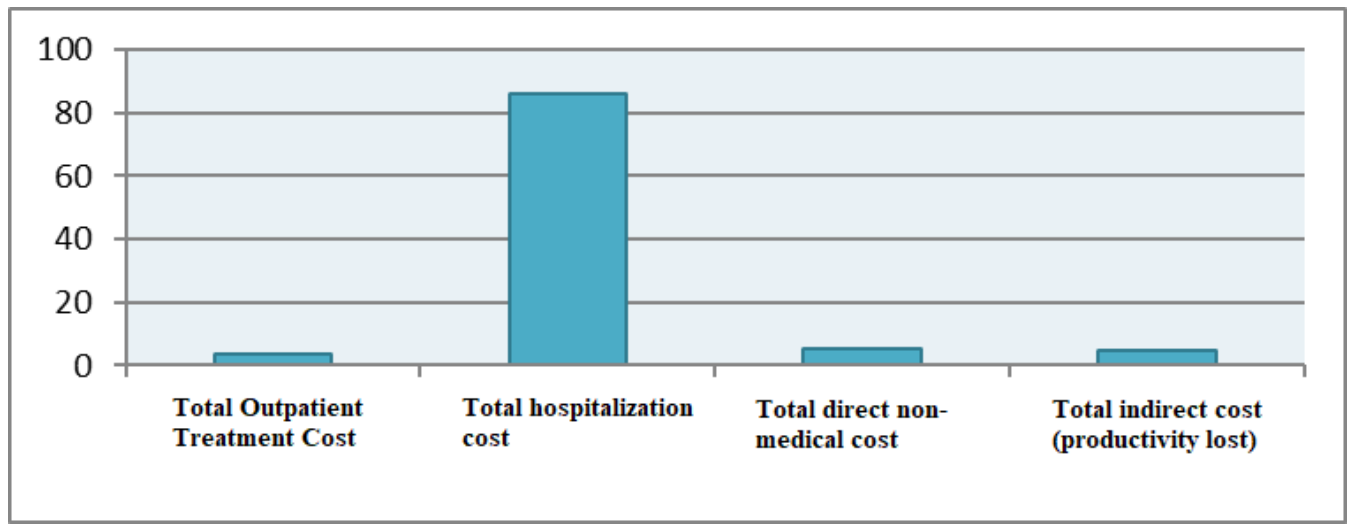

Diagram 1. Comparison of the Costs Associated with Cataract Disease to the Total Costs

It should be noted that this cost is for each patient and each eye, meaning that the costs would be doubled if both eyes of a patient were treated. Among the hospitalization costs, the highest costs were related to purchasing the operating room equipment (Diagram 2). 


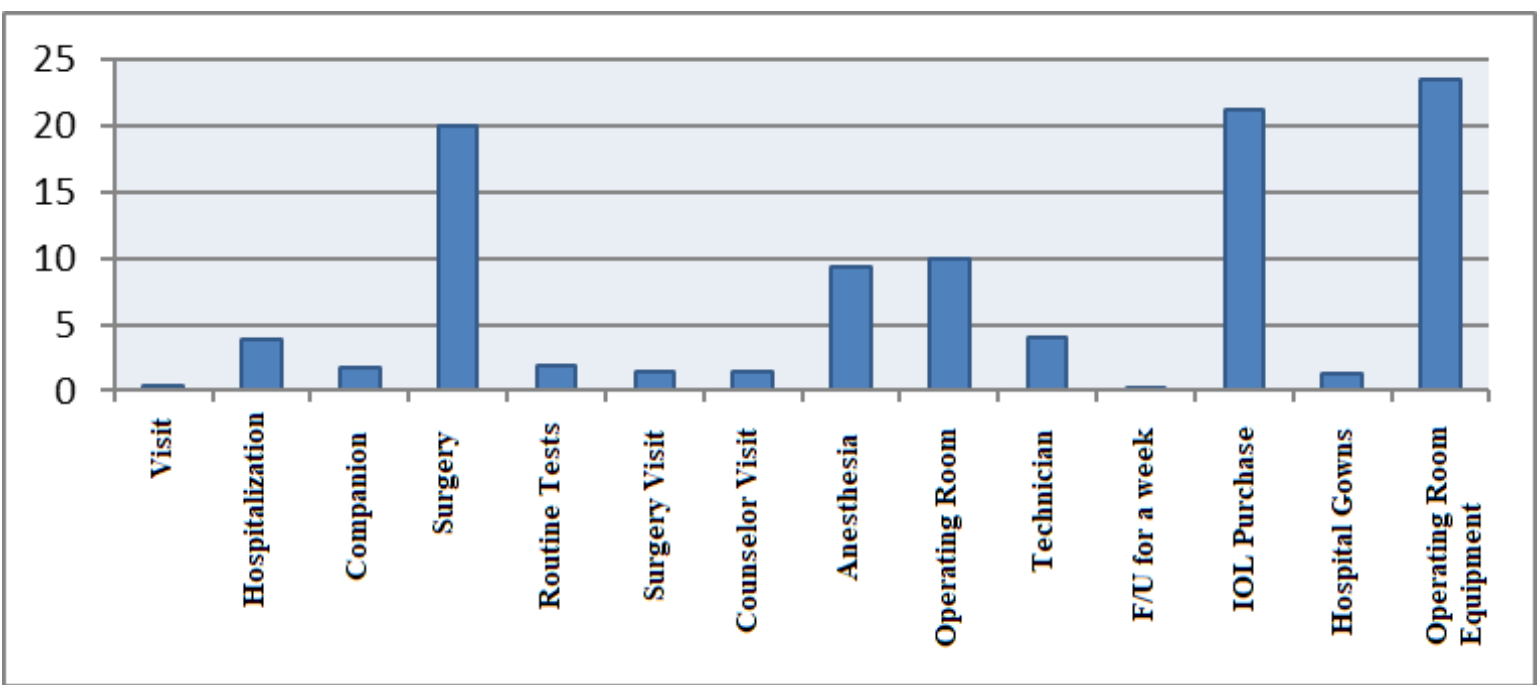

Diagram 2. The Proportion of Each Item of Hospitalization Cost for Cataract Patients from the Total Hospital Costs

\section{Discussion}

According to the results of the present study, female patients, midwives, self-employed individuals and employees referring to Farabi Eye Hospital used the highest rate of hospital services, which is in line with the results obtained by Wang (2001) in Japan (9). Similar to our findings, Hashemi concluded that there was a higher rate of female cataract patients undergoing surgeries, compared to male patients (6). On the other hand, selfemployed individuals were forced to take a day off in order to receive services. Meanwhile, the total estimated costs would be significantly higher if the income of these people exceeded the minimum wage of the country. In addition, employed patients impose an additional financial burden on the administrative system in case of taking a leave since their income is often higher than the minimum wage of the country. Although housewives do not directly raise financial costs, other family members are forced to compensate for their inability to pay. If the family members have an income and are forced to be absent from work, another cost would be imposed on the family or the administrative system.
In the current study, it was indicated that more than half of the patients had to take outbound travels, which increased the productivity lost costs for both patients and their companions. Given the heavy costs of cataract disease for the country, we must recognize the factors that increase the relevant costs and find solutions to reduce them. Studies have shown that one of the causes of increased treatment costs in eye diseases is worsening of the disease condition. Another important issue is the financial protection of families against the costs of this disease, especially the hospitalization costs since previous studies have demonstrated that the use of hospital services and increase of relevant costs upsurges the risk of household exposure to catastrophic health expenditures (18). This is especially important for the cataract disease since there is an extremely high rate of the condition among the population aged 40 years. Furthermore, it was reported that some of the costs, including IOL, hospital gowns, and costly equipment of the operating room, were directly paid by patients, which increased the risk of household exposure to catastrophic health expenditures. 
In addition, a high percentage of patients were forced to use their savings to pay for the healthcare services, which reduced the welfare level and increased poverty in the society, leading to a delay in treatment of patients by these individuals in most cases. Delay in treatment is equal to the worsening of the disease condition and forcing of patients to pay high costs for treatment, which increases poverty in the community and this reverse cycle continues.

Considering the importance of economic burdens related to visual impairments, it is suggested that preventive measures be taken and proper public health plans (e.g., educating the people, especially the less illiterate individuals) be designed in order to reduce the burden of this disease. In addition, it seems necessary to provide the facilities related to this condition to reduce the burden of the disease. One of the major drawbacks of the study was lack of participation of some of the patients in fast and timely completion of the questionnaire. Another limitation of the study was the lack of access to some of the desired information.

\section{Conclusion}

Given the fact that the Farabi Eye Hospital of Tehran is one of the most important cataract treatment centers in Iran and considering the stable therapeutic tariffs throughout the country, the results obtained from the medical files of this center can be generalized to the whole country to a great extent.

\section{Acknowledgements}

Hereby, we extend our gratitude to the authorities of Tehran University of Medical
Sciences and Farabi Eye Hospital for assisting us in performing this research.

\section{Declarations}

\section{Funding source(s)}

\section{Ethics approvals and consent to participate}

\section{Conflict of interest}

We declare that we have no financial or nonfinancial conflicts of interest related to the subject matter or materials discussed in the article.

\section{Authors' contributions}

All authors contributed equally to this work. 


\section{References}

1. Morone P, Cuena E.C, Kocur I, Banatvala $\mathrm{N}$. Investing in eye health: securing the support of decision-makers.Geneva: World Health Organization; 2012.

2. Foster A, Johnson G.J. Magnitude and causes of blindness in the developing world. International ophthalmology. 1991; 14(3): 135140.

3. Bamashmus M, Haider T, Al-Kershy R. Why is cataract surgery canceled? A retrospective evaluation. Eur J Ophthalmol. 2010; 20(1): 101105.

4. Jaffe, N.S. Cataract surgery and its complications. Mosby St. Louis; 1991.

5. Steinberg E.P., et al., The VF-14: an index of functional impairment in patients with cataract. Archives of Ophthalmology, 1994. 112(5): p. 630.

6. Hashemi H, Hatef E, Fotouhi A, Feizzadeh A, Kazem Mohammad A. The prevalence of lens opacities in Tehran: The
Tehran Eye Study. Ophthalmic epidemiology.2009; 16(3):187-192.

7. Akbari Sari A, Babashahy S, Olyaeimanesh S, Rashidian A. Estimating the Frequency and Rate of First 50 Common Types of Invasive Procedures in Iran Healthcare System. Iranian J Public Health, 2012,10(10): 60-64.

8. Rein D.B, Zhang P, Wirth K.E, Lee P.P, Hoerger T.J, McCall N, et al. The economic burden of major adult visual disorders in the United States. Archives of Ophthalmology. 2006;124(12): 1754-1760.

9. Wong TY. Cataract extraction rates among Chinese, Malays and Indians in Singapore: a population-based analysis. Arch Ophthalmol. 2001;119(5):727-732.

10. Rezapour A,Ghaderi H, EbadiFarbod Azar, Larijani B, Gohari M.R. Effects of Health Out-of-Pocket Payment on HouseHolds in Iran; Catastrophic and Impoverishment: Population Based Study in Tehran (2012). Life Science Journal issues. 2013; 10(3): 1457-1469.

\section{How to cite:}

Shakeri A.A, Sari A.A, Radin Manesh M, Fakhraei Gh, Fayazbakhsh A, Yousefi A. Estimation of Economic Burden of Cataract Disease in Iran: A Cross-sectional Research. Jorjani Biomedicine Journal. 2018; 6(2): $104-114$. DOI: 10.29252/jorjanibiomedj.6.2.107 